\title{
O Que os Países Escutam: Analisando a Rede de Gêneros Musicais ao Redor do Mundo
}

\author{
Maria Luiza Botelho Mondelli, Luiz M. R. Gadelha Jr., Artur Ziviani \\ ${ }^{1}$ Laboratório Nacional de Computação Científica (LNCC) \\ Petrópolis, RJ, Brasil \\ \{mluiza, lgadelha, ziviani\}@lncc.br
}

\begin{abstract}
Music streaming platforms are increasingly popular, democratizing and facilitating the access to music content. This effect extends the reach and the penetration of different musical styles, increasing the diversity of listened genres in different countries around the world. In order to better understand this diversity and identify countries with common interests, in this paper we build and analyze a complex network of artists, musical genres, and countries using data from Spotify, one of the most widely used music streaming platforms today. As results, in addition to identifying communities of countries with similar musical styles, we show how the large amount and diversity of musical genres can influence the modeling and analysis of the considered network. We also classify the most commonly listened genres using different centrality metrics.
\end{abstract}

Resumo. Plataformas de streaming de música são cada vez mais populares, democratizando e facilitando o acesso ao conteúdo musical. Esse efeito amplia o alcance e a penetração de diferentes estilos musicais, incrementando a diversidade de gêneros escutados nos diferentes países do mundo. A fim de melhor entender essa diversidade e identificar países com interesses em comum, neste artigo foi construída e analisada uma rede complex de artistas, gêneros musicais e países utilizando dados do Spotify, uma das plataformas de streaming de música mais utilizadas atualmente. Como resultados, além de identificar comunidades de países com estilos musicais semelhantes, nós mostramos como a grande quantidade e diversidade de gêneros musicais pode influenciar a modelagem e análise da rede considerada. Nós também classificamos os gêneros mais comumente escutados utilizando diferentes métricas de centralidade.

\section{Introdução}

A música é um tipo de arte cuja manifestação pode ser caracterizada como uma prática cultural. Seu papel está relacionado a aspectos como entretenimento e construção de identidade, memória e emoções em indivíduos [DeNora 2000]. Além disso, a música é comumente utilizada como uma forma de auto-expressão, fornecendo um meio de caracterizar e identificar, por exemplo, grupos de pessoas com interesses musicais em comum e também acontecimentos históricos [Rentfrow 2012].

Nas últimas décadas, o avanço da tecnologia tem exercido um papel importante na indústria da música, mudando a forma como ela é distribuída e consumida pelo público. Um exemplo disso consiste no surgimento das plataformas de streaming de música. Devido ao fato de permitirem o consumo em tempo real de músicas sem a necessidade de 
fazer o download de arquivos [Trefzger et al. 2015], essas plataformas têm recebido cada vez mais destaque. A grande adesão a esse tipo de serviço por parte dos usuários pode ser entendida como um fator que tem democratizado o acesso ao conteúdo musical. Isso pode ser observado a partir de dados do IFPI (International Federation of the Phonographic Industry) [IFPI 2017], que mostram que 50\% da receita da indústria fonográfica em 2016 foi proveniente do uso de plataformas de streaming de música e downloads.

Basicamente, através do serviço de streaming, usuários escutam músicas, que por sua vez são gravadas e disponibilizadas por artistas e bandas. Através dessa estrutura, é possível ainda registrar alguns metadados que incluem: gênero dos artistas, popularidade e quantidade de streams de determinada música, entre outros. A coleta e o armazenamento desse tipo de informação é um aspecto importante que surge com a popularização dessas plataformas e que abre espaço para um grande conjunto de possíveis estudos. Dentre eles, destaca-se a aplicação de técnicas de ciência de redes [Barabási 2016] para a análise da estrutura das plataformas, que podem ser facilmente caracterizadas como uma rede.

Neste contexto, o presente trabalho tem como objetivo analisar a rede de gêneros musicais ao redor do mundo. Para isto, utilizaremos o Spotify, uma plataforma de streaming de música bem consolidada e que disponibiliza os dados necessários para a construção da rede, que será composta por países, artistas e gêneros. Serão utilizados dados sobre as músicas mais tocadas em alguns dos países onde o Spotify está disponível. Esse tipo de estudo permitirá, por exemplo, entender quais são os gêneros mais tocados e identificar comunidades de países que compartilham gêneros musicais em comum.

Sendo assim, este artigo está organizado como segue. A Seção 2 descreve o processo de coleta de dados para a construção da rede. A Seção 3 apresenta o estudo e os resultados das análises da rede. A Seção 4 apresenta alguns trabalhos relacionados. Por fim, a Seção 5 conclui o trabalho e apresenta algumas oportunidades de trabalhos futuros.

\section{Conjunto de dados e construção da rede}

O Spotify é uma plataforma de streaming de música lançada em 2008 e que hoje reúne aproximadamente 30 milhões de músicas, 2 milhões de artistas e 140 milhões de usuários. Além de ser um serviço de streaming bem consolidado, o Spotify disponibiliza o acesso a parte de sua base de dados para consulta, possibilitando a construção da rede a ser analisada neste trabalho. Sendo assim, a seguir são descritas as duas fontes do Spotify utilizadas para a coleta de dados:

- Spotify Charts ${ }^{1}$ : registra, diária e semanalmente, uma lista de até 200 músicas mais escutadas nos países onde o Spotify está disponível e seus respectivos artistas. Para este trabalho, foram coletadas duas listas: a primeira referente ao dia 01/07/2017, com 9231 registros, totalizando 1326 artistas e 2438 músicas diferentes; e a segunda referente ao dia 01/01/2018, com 9219 registros e um total de 1609 artistas e 2995 músicas diferentes. Vale ressaltar que para a primeira listagem foi possível obter registros para 57 países, enquanto que para segunda foram obtidos registros para 50 países.

- Spotify Web $\mathrm{API}^{2}$ : disponibiliza metadados sobre artistas, álbuns e músicas do catálogo do Spotify. A API foi acessada a fim de recuperar os gêneros musicais

\footnotetext{
${ }^{1}$ https://spotifycharts.com/

${ }^{2}$ https://developer.spotify.com/web-api
} 
de cada um dos artistas obtidos nas listagens do Spotify Charts descritas anteriormente. Vale destacar que cada artista pode possuir mais de um gênero e que, de acordo com a plataforma Every Noise [Noise 2017], o Spotify possui um registro de aproximadamente 1500 gêneros diferentes. A consulta aos metadados da API permitiu então associar cada artista ao seu respectivo gênero principal, resultando em um total de 367 diferentes gêneros para o conjunto de dados do dia 01/07/2017 e 425 gêneros para o conjunto do dia 01/01/2018. O impacto da grande quantidade de gêneros será discutido na Seção 3, onde serão feitas as análises das redes.

A estrutura dos dados permitiu então a construção de uma rede tripartida, não direcionada, para cada uma das listagens coletadas. Nessa rede, os conjuntos de vértices podem ser classificados como: (i) países, (ii) artistas e (iii) gêneros musicais. As ligações entre as classes de vértices são apresentadas na Figura 1 e acontecem da seguinte forma:

- Países se conectam a artistas, segundo o registro obtido no Spotify Charts que relaciona cada música e seu respectivo artista aos países onde ele é mais escutado.

- Artistas se conectam aos gêneros, de acordo com os metadados obtidos através da API Web.

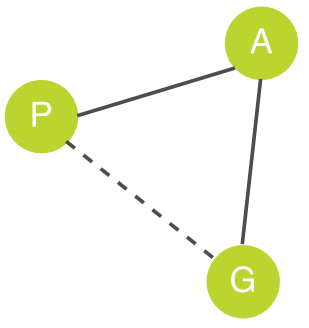

Figura 1. Exemplo da estrutura da rede de países, artistas e gêneros.

Com esse modelo, é possível ainda conectar cada país diretamente aos gêneros, por transitividade (linha tracejada na Figura 1). Essa conexão, que resulta na rede bipartida de país e gênero, será o objeto de estudo deste trabalho. Vale ainda ressaltar que, a construção dos conjuntos de dados e as análises apresentadas na seção a seguir, foram feitos utilizando o pacote estatístico R e estão disponíveis no GitHub ${ }^{3}$.

\section{Análise da rede de gêneros musicais}

Esta seção analisa a rede de gêneros musicais ao redor do mundo para cada uma das datas coletadas. Primeiramente, consideramos a rede completa de gêneros musicais e, em seguida, analisamos a rede com somente os principais gêneros musicais escutados. A fim de diferenciar os resultados das análises, nomeamos como Rede 1 e Rede 2 as redes que utilizam os dados dos dias 01/07/2017 e 01/01/2018, respectivamente.

\subsection{Análise das redes completas de gêneros musicais}

Para esta análise, consideramos o modelo de rede bipartida que relaciona os conjuntos de vértices país e gênero. A Rede 1 possui 57 países e 367 gêneros, totalizando 424 vértices e 3579 arestas. A Rede 2, por sua vez, possui 50 países e 424 gêneros, totalizando 474 vértices e 3835 arestas. Com a finalidade de entender o perfil musical de cada um dos

\footnotetext{
${ }^{3}$ https://github.com/mmondel li/network-science
} 
países e analisar as características das duas redes, foi realizada a projeção da rede de países conectados por gêneros em comum. Essa projeção resultou em uma rede completamente conectada, onde cada país está conectado aos demais, como mostra a Figura 2.

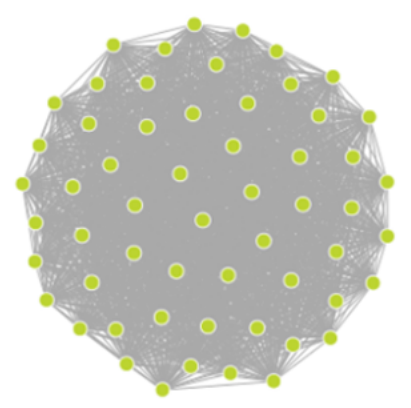

(a) Rede $1(01 / 07 / 2017)$

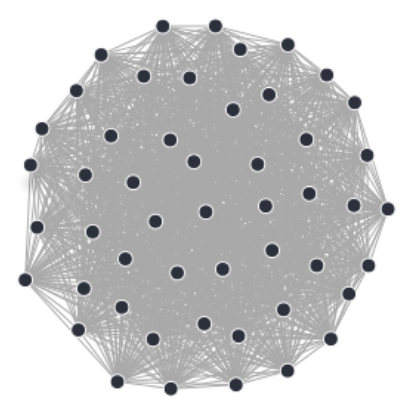

(b) Rede $2(01 / 01 / 2018)$

Figura 2. Projeção de países conectados por gênero em comum.

Analisando os dados, observa-se que isso ocorre devido a existência de pelo menos um gênero que ocorre em todos os países. Esse tipo de gênero pode ser classificado então como sendo um gênero universal, que é o caso do gênero pop, por exemplo. Além da existência de gêneros universais, outro aspecto pode ser observado: o fator viral de uma determinada música ou artista pode fazer com que um gênero também ocorra em todos os países, mesmo que pontualmente. Um exemplo disso consiste no gênero latin, que aparece em todos os países da Rede 1 devido à popularidade da música "Despacito" do cantor Luis Fonsi, identificada como a música mais escutada ao redor do mundo. Os motivos pelos quais um artista ou música tornam-se virais é uma questão bastante discutida atualmente, mas que foge do escopo deste trabalho. No entanto, no caso da música "Despacito", é possível atribuir parte da popularidade ao aumento do uso de plataformas de streaming de música e vídeo ${ }^{4}$.

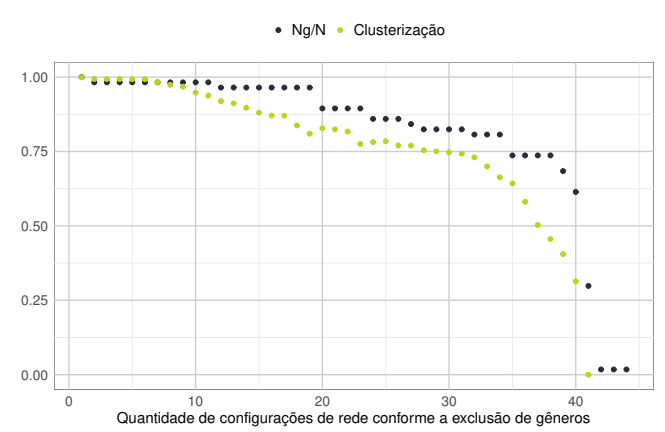

(a) Rede $1(01 / 07 / 2017)$

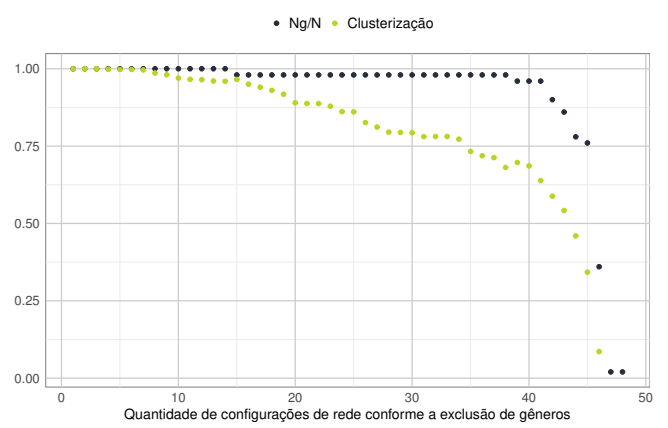

(b) Rede $2(01 / 01 / 2018)$

Figura 3. Comportamento da rede com a exclusão de gêneros.

Considerar a estrutura original dos conjuntos de dados deste trabalho impossibilita

\footnotetext{
${ }^{4}$ http://www.billboard.com/articles/columns/latin/7873798/ luis-fonsi-daddy-yankee-despacito-streaming-popularity
} 
o estudo das nuances acerca do perfil musical de cada um dos países, devido a existência de gêneros universais e músicas virais. Foi então realizada uma análise das Redes 1 e 2, a fim de entender seus comportamentos conforme uma determinada quantidade de gêneros fosse excluída. A exclusão foi feita iterativamente, de forma com que no primeiro passo fossem excluídos todos os gêneros que aparecem em todos os $n$ países, onde $n$ é o número total de países de cada rede. Depois foram excluídos os gêneros que aparecem em pelo menos $n-1$ países e assim por diante. Esse processo foi repetido até que não existissem mais gêneros a serem excluídos, totalizando 44 passos (ou redes diferentes) para a Rede 1 e 48 passos para a Rede 2. Foram contabilizados a fração de vértices do componente gigante $\left(N_{g}\right)$ em relação ao número total de vértices de cada rede $(N)$ e a clusterização em cada caso. O resultado é apresentado na Figura 3. É possível perceber que, em ambos os casos, a clusterização tende a permanecer alta. O componente gigante abrange a maioria dos nós da rede por muitos passos, diminuindo de forma mais significativa apenas quando restam poucos gêneros a serem excluídos. Sendo assim, escolher um limite de gêneros a ser considerado nesse caso para prosseguir com a caracterização da rede não é trivial. Neste trabalho, optou-se então por analisar apenas os gêneros mais frequentes em cada um dos países, conforme descreve a subseção a seguir.

\subsection{Análise da rede para os 5 gêneros musicais mais escutados}

Como observado na análise das redes com a exclusão de gêneros, existe uma sensibilidade no que diz respeito ao estado das redes que pode ser considerado para a continuação do estudo. Sendo assim, neste trabalho optou-se por fazer uma filtragem nos dados, de forma a considerar apenas os cinco gêneros mais frequentemente escutados em cada país. Vale ressaltar também que, para a construção destas redes, foram excluídos gêneros que aparecem em pelo menos $90 \%$ dos países, a fim de evitar as redes completamente conectadas e também de possibilitar o aparecimento de gêneros mais característicos de cada país.

A rede bipartida de países e gêneros, no caso da Rede 1, possui 157 vértices e 259 arestas. Para o caso da Rede 2, possui 155 vértices e 250 arestas. As redes podem ser analisadas a partir de suas projeções ponderadas. A Tabela 1 mostra as características das projeções, onde: (i) Países diz respeito à projeção de países conectados por gêneros em comum; e (ii) Gêneros é a projeção de gêneros conectados por países em comum. Em comparação ao que é esperado para redes aleatórias equivalentes às duas projeções das Redes 1 e 2, observa-se que ambas possuem distância e diâmetro baixos e alta clusterização. Além disso, é possível observar que as redes são bem conectadas, com grande parte dos vértices pertencendo ao maior componente conexo.

\subsubsection{Ranqueamento dos gêneros musicais}

A partir da projeção de gêneros conectados por países em comum, foi possível obter o ranqueamento dos gêneros mais centrais para as Redes 1 e 2. As Tabelas 2 e 3 apresentam uma listagem dos primeiros 5 gêneros classificados de acordo com três diferentes métricas de centralidade descritas a seguir:

- Grau: é considerada a medida mais simples de centralidade em redes e está relacionada à quantidade de conexões que um determinado vértice possui. Sendo assim, quanto mais conexões, maior a importância do vértice na rede. Para redes direcionadas, a centralidade de grau leva em consideração a direção da conexão. 
Tabela 1. Características das projeções da rede bipartida de gêneros e países (top 5).

\begin{tabular}{|l|r|r|r|r|}
\multicolumn{1}{c|}{} & \multicolumn{2}{c|}{ Rede 1 } & \multicolumn{2}{c|}{ Rede 2 } \\
\hline Características & Países & Gêneros & Países & Gêneros \\
\hline Vértices & 56 & 101 & 50 & 105 \\
\hline Arestas & 459 & 310 & 357 & 327 \\
\hline Grau máximo & 36 & 26 & 33 & 40 \\
\hline Grau mínimo & 0 & 3 & 0 & 4 \\
\hline Grau médio & 16.3 & 6.1 & 14.3 & 6.2 \\
\hline Distancia média & 1.76 & 2.6 & 2.06 & 2.8 \\
\hline Diâmetro & 5 & 7 & 9 & 9 \\
\hline Clusterização & 0.79 & 0.43 & 0.8 & 0.39 \\
\hline Densidade & 0.29 & 0.06 & 0.29 & 0.005 \\
\hline Componentes & 6 & 6 & 3 & 3 \\
\hline Tamanho maior componente & $91 \%$ & $75 \%$ & $96 \%$ & $90 \%$ \\
\hline
\end{tabular}

- Closeness: calcula o comprimento médio dos caminhos mais curtos de um vértice para cada um dos demais vértices que compõem a rede. Quanto maior a centralidade de um determinado vértice, menor é a sua distância para os demais.

- Betweenness: estabelece a importância de um vértice com base na quantidade de caminhos mínimos pelos quais ele faz parte. Em outras palavras, esse tipo de centralidade quantifica o número de vezes em que um vértice atua como ponte no caminho mais curto entre dois outros vértices.

A respeito dos resultados de ranqueamento obtidos, vale ressaltar que a frequência com que esses gêneros aparecem em cada país não está sendo levada em consideração, mas sim se eles aparecem pelo menos uma vez, de acordo com a filtragem proposta nesta seção. O gênero southern hip hop, por exemplo, é mais frequente nos Estados Unidos e Canadá, enquanto que o reggaetown é frequente nos países da América Latina em geral. Em um trabalho futuro, uma oportunidade estaria em considerar a frequência dos gêneros nas análises.

Por se tratar de uma rede bipartida, a interpretação dos ranqueamentos apresentados nas Tabelas 2 e 3 deve levar em consideração o fato de que os gêneros estão conectados se possuem pelo menos um país em comum. Através dos dados da Rede 1 foi possível identificar que o gênero southern hip hop está presente em apenas 14 países, enquanto que o reggaeton aparece em 22 países. No entanto, comparando os dois casos, os países que escutam southern hip hop são mais distintos entre si, fazendo com que ele se conecte a mais gêneros e por isso possua maior centralidade de grau. Esse mesmo aspecto foi observado através de uma varredura nos dados da Rede 2, onde existem gêneros como vegas indie e progressive house que estão presentes em mais países do que os listados no ranqueamento, mas que não possuem alta centralidade de grau. Outro fator que pode ser observado é a similaridade dos resultados das métricas closeness e betwenness, principalmente para a Rede 1. Esses resultados para closeness e betwenness sugerem que os gêneros listados atuam tanto aproximando os países com estilos musicais em comum, quanto conectando países que possuem maior diversidade de gêneros musicais, respectivamente. 
Além disso, é possível observar a classificação de gêneros como west coast rap, latin hip hop, trap music e trap latino dentre os gêneros mais centrais, mesmo com a exclusão dos gêneros rap, hip hop e latin. Isso mostra que, de alguma forma, esses últimos três gêneros ainda estão presentes através de suas variações, indicando sua importância na rede. Isso também ocorre com o neo mellow que, de acordo com mapa construído pelo Every Noise [Noise 2017], é um gênero muito similar ao pop, que também não está presente em nenhuma das redes.

Tabela 2. Ranqueamento dos gêneros musicais para a Rede 1.

\begin{tabular}{|c|c|c|c|}
\hline & Grau & Closeness & Betweenness \\
\hline 1 & southern hip hop & reggaeton & reggaeton \\
\hline 2 & reggaeton & neo mellow & neo mellow \\
\hline 3 & neo mellow & southern hip hop & southern hip hop \\
\hline 4 & west coast rap & west coast rap & deep tropical house \\
\hline 5 & tropical & deep tropical house & west coast rap \\
\hline
\end{tabular}

Tabela 3. Ranqueamento dos gêneros musicais para a Rede 2.

\begin{tabular}{|c|c|c|c|}
\hline & Grau & Closeness & Betweenness \\
\hline 1 & trap music & southern hip hop & trap music \\
\hline 2 & big room & trap music & southern hip hop \\
\hline 3 & tropical & rock & viral pop \\
\hline 4 & southern hip hop & deep funk carioca & tropical \\
\hline 5 & viral pop & viral pop & big room \\
\hline
\end{tabular}

\subsubsection{Países com interesses musicais em comum}

A identificação de comunidades em ciência de redes pode ser entendida como a busca por grupos de nós que possuem maior probabilidade de se conectarem entre si do que a nós de outras comunidades [Barabási 2016]. Sendo assim, comunidades reúnem um conjunto de nós que estão mais conectados internamente do que com outros nós em uma rede aleatória equivalente. Partindo dessa definição e da projeção de países conectados por gêneros, este trabalho buscou identificar os grupos de países que possuem interesses em comum. Para isso, foi aplicado o método de Louvain [Blondel et al. 2008], que possui uma abordagem baseada na otimização da modularidade e é considerado o estado da arte para detecção de comunidades em redes. Basicamente, em um primeiro momento, o método atribui cada vértice a uma comunidade. O método segue de forma iterativa, reatribuíndo os vértices às comunidades de forma com que eles se movam para as comunidades onde contribuem mais para a modularidade. Quando nenhum vértice pode ser mais reatribuído, o processo continua, mas considerando as comunidades como sendo os vértices. O processo é finalizado quando a modularidade global máxima é encontrada.

Como resultado, na Rede 1 foram encontrados 8 comunidades de países. Dessas comunidades, 5 são comunidades individuais de países que não estavam conectados ao maior componente da rede, sendo eles: Japão, Finlândia, Noruega, Turquia e Suécia. Com a filtragem dos 5 gêneros mais frequentes proposta na análise desta seção, esses 


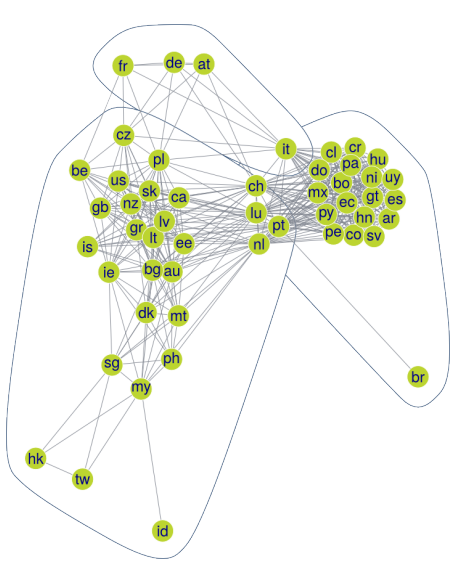

(a) Rede $1(01 / 07 / 2017)$

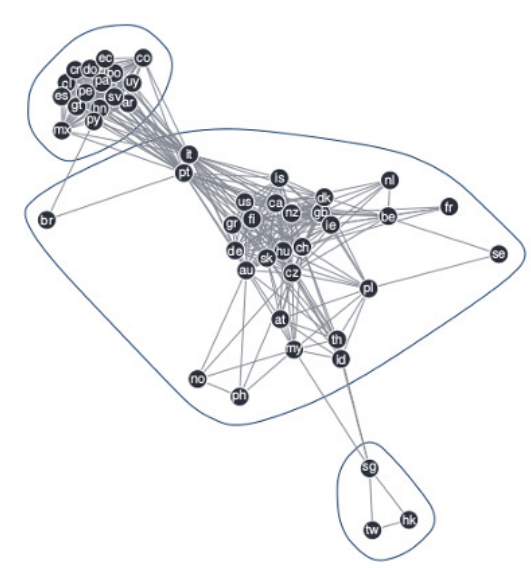

(b) Rede $2(01 / 01 / 2018)$

Figura 4. Comunidades de países identificada pelo método de Louvain.

países passaram a não compartilhar nenhum gênero com os demais. No caso do Japão por exemplo, os gêneros mais comuns são o anime, juntamente com variações regionais do pop, rap, $r \& b$ e rock. As outras 3 comunidades são apresentadas na Figura 4(a) e descritas a seguir:

1. Argentina, Bolívia, Chile, Colômbia, Costa Rica, República Dominicana, Equador, Espanha, Guatemala, Honduras, México, Nicarágua, Panamá, Perú, Paraguai, São Salvador e Uruguai, Brasil, Portugal, Hungria e Suíça.

2. Áustria, Alemanha, Itália e França.

3. Estados Unidos, Reino Unido, Austrália, Bélgica, Bulgaria, Canadá, República Checa, Dinamarca, Estônia, Gŕecia, Holanda, Hong Kong, Indonésia, Irlanda, Islândia, Lituânia, Letônia, Luxemburgo, Malta, Malásia, Nova Zelândia, Filipinas, Polônia, Singapura, Eslováquia e Taiwan.

É interessante notar que, na comunidade 1 foram claramente agrupados a maioria dos países de línguas espanhola e castelhana. A comunidade 2 agrupou alguns países da Europa. A comunidade 3 por sua vez é a maior e mais diversificada, possuindo países da Europa, Ásia, América do Norte e Oceania.

Para a Rede 2 foi identificado um total de 5 comunidades, onde 2 são comunidades individuais dos países Japão e Turquia. No caso da Rede 1, esses dois países também não fazem parte de nenhuma outra comunidade, sugerindo que de fato eles possuem predileção por estilos musicais próprios. As demais comunidades, apresentadas na Figura 4(b), são listadas a seguir:

1. Argentina, Bolívia, Chile, Colômbia, Costa Rica, República Dominicana, Equador, Espanha, Guatemala, Honduras, México, Panamá, Peru, Paraguai, São Salvador e Uruguai.

2. Hong Kong, Singapura e Taiwan.

3. Estados Unidos, Reino Unido, Áustria, Austrália, Bélgica, Brasil, Canadá, Suíça, República Checa, Alemanha, Dinamarca, Finlândia, França, Grécia, Hungria, Indonésia, Irlanda, Islândia, Itália, Malásia, Holanda, Noruega, Nova Zelândia, Filipinas, Polônia, Portugal, Suécia, Eslováquia e Tailândia.

Observa-se que, diferentemente do resultado da Rede 1, a comunidade 1 não agrupa nenhum outro país que não seja de língua espanhola ou castelhana. A comunidade 2 passou 
a agrupar países da Ásia e a comunidade 3 continua sendo a maior e mais diversificada.

Apesar dos agrupamentos, em ambos os casos percebe-se ainda que muitos países de uma comunidade se conectam a países de outras comunidades, podendo indicar que de fato eles são parecidos musicalmente ou ser consequência da grande quantidade de gêneros diferentes que existem mesmo com os filtros aplicados. No geral, observamos que o comportamento dos agrupamentos nas Redes 1 e 2 mantém um padrão. No entanto, as diferenças pontuais podem acontecer devido a filtragem de gêneros que foi proposta nesta seção e também ser consequência das músicas que são listadas como populares em cada um dos períodos. A identificação de comunidades nesse tipo de rede pode também sugerir a existência de zonas de influência de determinados gêneros em grupos de países, podendo ser objeto de estudo em análises mais detalhadas no futuro.

\subsubsection{Quantos gêneros de um determinado país são de fato dele?}

A plataforma Every Noise desenvolveu um mecanismo onde, além de identificar todos os gêneros musicais existentes a partir de características das músicas (incluindo aspectos sobre acústica, energia, entre outros), é possível atribuir os gêneros ao seu país considerado origem. Essa informação está também disponível através de seu site. Considerando então os 5 gêneros mais frequentes em cada um dos países, é possível determinar qual é a proporção desses gêneros que são de fato locais.

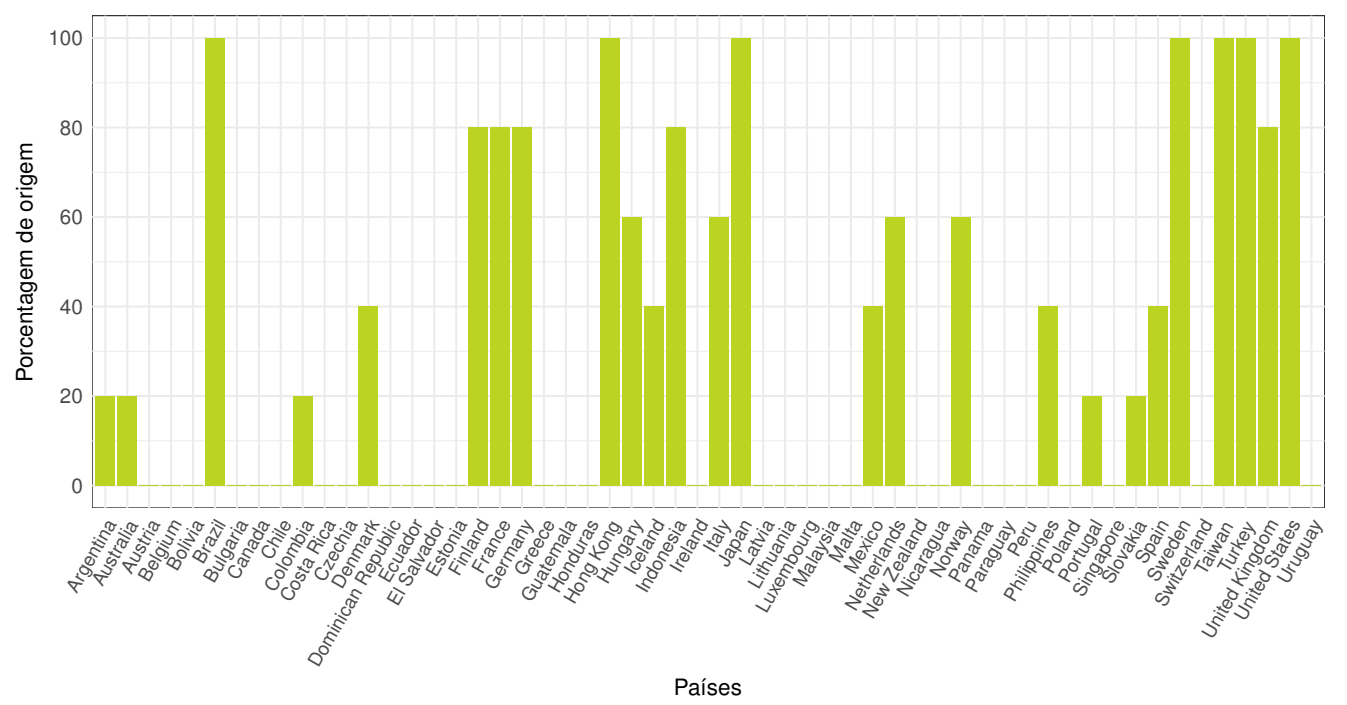

Figura 5. Proporção de gêneros que são originados em cada país.

Essa análise foi realizada para as Redes 1 e 2 mas, devido à similaridade dos resultados, optou-se por apresentar apenas um deles. Sendo assim, para cada país presente na Rede 1, os gêneros da rede foram comparados com a relação de gêneros e países da plataforma Every Noise. A Figura 5 mostra o resultado dessa comparação, onde 100\% indica que os 5 gêneros de um país são de origem dele. Dos 57 países da Rede 1, apenas 12 possuem pelo menos $80 \%$ de gêneros considerados originais. Ou seja, pode-se dizer que, elimnando os gêneros universais existe pouca influência de outros países no estilo musical desse conjunto de 12 países. Por outro lado, um grande conjunto de países são 
completamente influenciados ou importam gêneros musicais dos demais. O resultado desse tipo de análise pode também estar relacionado à produção musical própria de um determinado país. Em outras palavras, países que possuem uma indústria musical bem estabelecida podem estar produzindo um conteúdo mais voltado às suas questões culturais e costumes. Um exemplo disso é o Brasil, onde o forró, o funk carioca e o sertanejo e suas variações foram classificados como os gêneros mais escutados. Esse tipo de análise permite que estudos futuros busquem entender como ocorre a influência e o fluxo de estilos musicais entre países, identificar quais são os países mais influentes e explorar a estrutura da produção musical em cada país, por exemplo.

\section{Trabalhos relacionados}

O trabalho proposto por [Lee and Cunningham 2012] estuda o fluxo de música entre diferentes regiões do mundo, utilizando dados da plataforma de streaming de música Last.fm. O estudo busca entender quais são as preferências musicais de cada região e determinar os agrupamentos entre elas. São estabelecidas relações do tipo líder-seguidor entre os nós, permitindo entender qual é a dinâmica da preferência musical na rede. No entanto, como visto neste trabalho, a existência da grande quantidade de gêneros é um fator que influencia a estrutura de redes que visam estudar preferências músicais entre países. Em [Lee and Cunningham 2012] não fica claro qual foi a quantidade de gêneros considerada para o estudo e se houve ou não algum tipo de filtragem.

Em [Bryan and Wang 2011], a partir de dados da plataforma WhoSampled, são classificados os gêneros e artistas mais influentes no mercado musical de sampling. Sampling diz respeito à seleção de uma amostra de gravação de som a fim de reutilizá-la em uma outra gravação diferente. Sendo assim, um registro no conjunto de dados consiste em um artista que teve sua música amostrada e o artista que utilizou a amostra, incluindo metadados como o gênero. Esse tipo de dado possibilitou a construção de três redes direcionadas de músicas, artistas e gêneros. Em comparação com o presente trabalho, a abordagem em questão não aborda a grande diversidade de gêneros e difere no que diz respeito à estrutura da rede e ao tipo de dado que foi analisado.

A diversidade de gêneros é abordada em [Lambiotte and Ausloos 2006] com o foco no comportamento dos usuários em geral, e não nos países, como foi feito neste trabalho. São utilizados dados do Last.fm a fim de identificar padrões coletivos a partir das músicas escutadas. $\mathrm{O}$ trabalho identificou um total de 142 gêneros distintos, divididos em grupos musicais. A partir da correlação entre os gêneros, obteve-se um mapa onde foi possível observar que determinados gêneros musicais tendem a ser escutados pelos mesmos usuários. Em [Lambiotte and Ausloos 2005] a estrutura dessa mesma rede é explorada de forma aleatória a fim de mapear a estrutura interna da rede e as correlações em uma série temporal. A análise estatística dessa série permitiu identificar comportamentos não-triviais de usuários sugerindo, por exemplo, que eles se tornam mais ecléticos musicalmente.

A busca por comunidades em redes de música é também estudada em [Smith 2006] e [Gleiser and Danon 2003]. No entanto, ambos os trabalhos levam em consideração gêneros musicais específicos. Em [Smith 2006] é analisada a estrutura da rede de colaboração entre cantores de rap e em [Gleiser and Danon 2003] é analisada a rede de cantores de jazz. Neste último foi possível identificar a segregação racial entre as 
comunidades de artistas encontradas.

Em contraste, o presente trabalho apresentou uma visão da rede de gêneros musicais escutados ao redor do mundo a partir dos dados do Spotify. O Spotify se destaca pela sua popularidade e pelo seu esforço em aprimorar a experiência do usuário no que diz respeito ao consumo de conteúdo musical. [Vlegels and Lievens 2017] destaca que estudos desse tipo de rede podem não refletir a possibilidade de mudanças nas características dos gêneros. No entanto, o Spotify classifica os gêneros musicais através de algoritmos que utilizam informações específicas das músicas, tais como força da batida e energia. Sendo assim, a estrutura da rede analisada reflete a grande quantidade de novos gêneros descobertos pela plataforma e não exclui as características intrínsicas a cada um deles.

\section{Conclusões e trabalhos futuros}

Neste trabalho, foi construída uma rede de países e gêneros com base no registro de músicas mais escutadas em cada país disponibilizado pelo Spotify. O modelo de rede foi estudado a partir de dois conjuntos de dados, coletados através da plataforma em duas datas diferentes. Dessa forma, demonstramos que a metodologia utilizada para as análises não se restringe à uma data específica. A análise da projeção de países conectados por gêneros em comum permitiu identificar o impacto que a quantidade de gêneros exerce sobre a estrutura da rede, com base nos conjuntos de dados utilizados. Gêneros considerados universais e virais foram responsáveis por conectar todos os países entre si.

Uma vez que o trabalho teve como objetivo entender o estilo musical dos países, foi feita uma filtragem que buscou excluir os gêneros universais e, a partir disso, considerar apenas os 5 gêneros mais frequentes em cada país. Com essa nova configuração de rede, foi possível classificar os gêneros não universais segundo métricas de centralidade de redes. A classificação mostra que, mesmo com a exclusão dos gêneros universais, esses mesmos gêneros continuam presentes através de suas variações (ou subgêneros), demonstrando sua importância no cenário musical como um todo. Além disso, com a aplicação do método de Louvain foram identificadas comunidades de países que compartilham interesses musicais em comum. Para os dois conjuntos de dados utilizados, foi interessante observar o surgimento de uma comunidade que agrupou países de língua espanhola e castelhana. Esse tipo de comunidade destaca que, apesar da língua falada nesses países não ter sido um atributo levado em consideração no conjunto de dados, esses países tendem a ter estilos musicais parecidos. Trabalhos futuros poderiam incluir as características específicas dos gêneros, como ocorre em sistemas de recomendação e classificação [Shakya et al. 2017], a fim de se obter uma análise mais detalhada sobre as relações musicais entre países.

Uma das análises do trabalho identificou qual a proporção de gêneros escutada por um país é de fato dele. Essa análise mostra que para um grande conjunto de países, os gêneros são provenientes de outros. Um trabalho futuro pode analisar como ocorre esse fluxo de gêneros entre países. Também como trabalho futuro, observa-se a possibilidade de analisar a rede com foco nos artistas. Essa perspectiva permitirá, por exemplo, identificar quais são os artistas responsáveis pelo surgimento de determinados gêneros nos países e classificar os artistas mais influentes tanto global quanto regionalmente. Pode-se ainda estudar a variação da rede deste trabalho no tempo, uma vez que o registro das músicas mais escutadas em cada país é feito diariamente. Com isso, seria possível entender o 
comportamento de gêneros que, numa primeira análise não são universais, mas pelo fator viral de determinada música passam a conectar todos os países.

\section{Agradecimentos}

Agradecemos o suporte da CAPES, CNPq, FAPERJ e FAPESP.

\section{Referências}

Barabási, A.-L. (2016). Network science. Cambridge University Press.

Blondel, V. D., Guillaume, J.-L., Lambiotte, R., and Lefebvre, E. (2008). Fast unfolding of communities in large networks. Journal of statistical mechanics: theory and experiment, 2008(10):P10008.

Bryan, N. J. and Wang, G. (2011). Musical influence network analysis and rank of samplebased music. In ISMIR, pages 329-334.

DeNora, T. (2000). Music in everyday life. Cambridge University Press.

Gleiser, P. M. and Danon, L. (2003). Community structure in jazz. Advances in complex systems, 6(04):565-573.

IFPI (2017). IFPI facts and stats. http://www. ifpi.org/facts-and-stats . php. Acessado em: 01/09/2017.

Lambiotte, R. and Ausloos, M. (2005). Uncovering collective listening habits and music genres in bipartite networks. Physical Review E, 72(6):066107.

Lambiotte, R. and Ausloos, M. (2006). On the genre-fication of music: a percolation approach. The European Physical Journal B-Condensed Matter and Complex Systems, 50(1):183-188.

Lee, C. and Cunningham, P. (2012). The geographic flow of music. In Proceedings of the International Conference on Advances in Social Networks Analysis and Mining, pages 691-695. IEEE Computer Society.

Noise, E. (2017). Every Noise at Once. http: / / everynoi se. com/engenremap. html. Acessado em: 01/09/2017.

Rentfrow, P. J. (2012). The role of music in everyday life: Current directions in the social psychology of music. Social and personality psychology compass, 6(5):402-416.

Shakya, A., Gurung, B., Thapa, M. S., Rai, M., and Joshi, B. (2017). Music classification based on genre and mood. In International Conference on Computational Intelligence, Communications, and Business Analytics, pages 168-183. Springer.

Smith, R. D. (2006). The network of collaboration among rappers and its community structure. Journal of Statistical Mechanics: Theory and Experiment, 2006(02):P02006.

Trefzger, T., Rose, M., Baccarella, C., and Voigt, K.-I. (2015). Streaming killed the download star! how the business model of streaming services revolutionizes music distribution. Journal of Organizational Advancement (Online), Strategie and Institutional Studies, 7(1):29-39.

Vlegels, J. and Lievens, J. (2017). Music classification, genres, and taste patterns: A ground-up network analysis on the clustering of artist preferences. Poetics, 60:76-89. 